\title{
Exercise training in pulmonary arterial hypertension associated with connective tissue diseases
}

\author{
Ekkehard Grünig ${ }^{1 * \dagger}$, Felicitas Maier ${ }^{1 \dagger}$, Nicola Ehlken ${ }^{1}$, Christine Fischer ${ }^{2}$, Mona Lichtblau', Norbert Blank ${ }^{3}$, \\ Christoph Fiehn ${ }^{4}$, Frank Stöckl ${ }^{5}$, Felix Prange ${ }^{1}$, Gerd Staehler ${ }^{6}$, Frank Reichenberger ${ }^{7}$, Henning Tiede ${ }^{7}$, \\ Michael Halank ${ }^{8}$, Hans-Jürgen Seyfarth ${ }^{9}$, Simone Wagner ${ }^{10+}$ and Christian Nagel ${ }^{1+}$
}

\begin{abstract}
Introduction: The objective of this prospective study was to assess short- and long-term efficacy of exercise training (ET) as add-on to medical therapy in patients with connective tissue disease-associated pulmonary arterial hypertension (CTD-APAH).

Methods: Patients with invasively confirmed CTD-APAH received ET in-hospital for 3 weeks and continued at home for 12 weeks. Efficacy parameters have been evaluated at baseline and after 15 weeks by blinded-observers. Survival rate has been evaluated in a follow-up period of $2.9 \pm 1.9$ years.

Results: Twenty-one consecutive patients were included and assessed at baseline, and after 3 weeks, 14 after 15 weeks. Patients significantly improved the mean distance walked in 6 minutes compared to baseline by $67 \pm 52$ meters after 3 weeks $(p<0.001)$ and by $71 \pm 35$ meters after 15 weeks $(p=0.003)$, scores of quality of life $(p<$ 0.05 ), heart rate at rest, peak oxygen consumption, oxygen saturation and maximal workload. Systolic pulmonary artery pressure and diastolic systemic blood pressure improved significantly after 3 weeks of ET. The 1- and 2-year overall-survival rates were 100\%, the 3-year survival 73\%. In one patient lung transplantation was performed 6 months after ET.
\end{abstract}

Conclusion: ET as add-on to medical therapy is highly effective in patients with CTD-APAH to improve work capacity, quality of life and further prognostic relevant parameters and possibly improves the 1-, 2- and 3-year survival rate. Further randomized controlled studies are needed to confirm these results.

Trial registration: ClinicalTrials.gov: NCT00491309.

\section{Introduction}

Pulmonary arterial hypertension (PAH) is characterized by increased pulmonary arterial pressure and pulmonary vascular resistance [1] and can be associated with connective tissue disease (CTD) such as systemic sclerosis (SSc) [2] systemic lupus erythematosus (SLE) [3,4] and mixed connective tissue diseases (MCTD) [5]. Associated PAH (APAH) accounts for approximately half of all patients with PAH [6] and has identical histological

\footnotetext{
* Correspondence: ekkehard.gruenig@thoraxklinik-heidelberg.de

† Contributed equally

${ }^{1}$ Centre for Pulmonary Hypertension at Thoraxclinic Heidelberg, Thoraxclinic at the University Hospital Heidelberg, Amalienstraße 5, Heidelberg, 69126, Germany

Full list of author information is available at the end of the article
}

findings as idiopathic PAH (IPAH). However, patients with CTD-APAH seem to have a more severely affected clinical phenotype than patients with IPAH. In the American Registry to Evaluate Early and long Term PAH Disease Management (REVEAL Registry), patients with CTD-APAH had a significantly lower 6-minute walking distance (6MWD), higher B-type natriuretic peptide levels, lower diffusing capacity of carbon monoxide and a lower 1-year survival rate than patients with IPAH [7]. Despite advances in PAH treatment, CTDAPAH continues to be progressive, with a 1-year ontreatment mortality of approximately 12.5 to $17.0 \%$ compared to 5.0 to $10.0 \%$ in IPAH $[7,8]$. In comparison to other forms of APAH, patients with SSc-APAH 
demonstrated the worst 1-, 2- and 3-year survival rates of $78.0 \%, 58.0 \%$ and $47.0 \%$, respectively [9]. Patients with CTD-APAH showed a significantly reduced time to hospitalization, had a higher mean age at diagnosis and higher incidence of comorbidities such as renal insufficiency and Raynaud's phenomenon $[7,10]$. Furthermore, randomized controlled studies reveal reduced efficacy of PAH-targeted medication in this subgroup. For example, in the BREATHE-1 study, bosentan therapy improved baseline 6MWD by 46 meters in 102 patients with IPAH, but only by 3 meters in the 33 patients with SScAPAH [11]. In addition, therapy with ambrisentan resulted in significant improvement in the 6MWD among patients with IPAH but not with CTD-APAH [12]. Thus, patients with CTD-APAH in particular, may have a high need for additional therapeutic tools to address their exercise capacity, quality of life (QoL) and survival.

Exercise training (ET) has shown beneficial effects on exercise capacity and QoL in patients with PAH [13-15], SLE [16] and in SSc [17-19]. ET also improved peak oxygen consumption and World Health Organization functional class (WHO-FC) in patients with pulmonary hypertension [13], and possibly clinical outcomes, with 1 - and 2-year survival rates of 100 and $95 \%$, respectively [14]. Up to now there has been no study focusing on the effect of exercise training in patients with CTDAPAH. The aim of this study was to prospectively assess the effects of ET on prognostic relevant factors such as 6MWD and QoL, and to analyze the survival rate in a cohort of patients with CTD-APAH.

\section{Materials and methods Study population and design}

This prospective study investigated patients with CTDAPAH who received exercise and respiratory training as an add-on to disease-targeted medication, between October 2007 and July 2011. Further inclusion criteria were that patients must be aged between 18 and 80 years and classified as WHO-FC II to IV. Patients had to be under optimized medical therapy for PAH (endothelin-antagonists, inhaled or parenteral prostanoids, phosphodiesterase-5-inhibitors, anticoagulants, diuretics, and supplemental oxygen) and for the underlying rheumatologic disease (prednisone, methotrexate) for at least 2 months before entering the study. The diagnosis of CTD-APAH was established at the participating pulmonary hypertension $(\mathrm{PH})$ centers according to current guidelines $[1,15]$. The rheumatologic diagnosis of each patient had been confirmed by specialized rheumatologic centers. Patients with severe interstitial lung disease were excluded from the study. All patients underwent a detailed clinical work up including right heart catheterization, and all gave written informed consent for this study, which was approved by the Ethics Committee of the University of Heidelberg.

\section{Outcome measures}

Efficacy parameters of ET were prospectively assessed at baseline, week 3, and week 15 as described previously $[13,14]$. The $6 \mathrm{MWD}$ was carried out under standardized conditions [20]. Cardiopulmonary exercise testing and stress Doppler echocardiography were performed during supine bicycle exercise as described previously [13]. Systolic pulmonary artery pressure (sPAP), systolic (RRsys) and diastolic (RRdiast) systemic blood pressure, workload, heart rate, ventilation, oxygen uptake $\left(\mathrm{VO}_{2}\right)$, oxygen pulse $\left(\mathrm{VO}_{2} /\right.$ heart rate), oxygen saturation and carbon dioxide output $\left(\mathrm{VCO}_{2}\right)$ were evaluated continuously. The anaerobic threshold (AT) was detected with the V-slope method. Gas exchange, Borg dyspnea index (with 6 representing no exertion and 20 maximal exertion) [21] and changes in WHO-FC were analyzed after 3 and 15 weeks. Health-related QoL assessment was measured by the Short Form Health Survey questionnaire (SF-36) [22]; the baseline scores were compared to the results after 15 weeks. The 6MWD and analysis of the SF-36 questionnaire were performed by investigators who were blinded to the patients' clinical data, so that the investigators did not know the values at any time point.

\section{Exercise training program}

We performed a program especially developed for patients with $\mathrm{PH}$, that comprised at least $1.5 \mathrm{~h}$ /day ET as described previously $[13,14]$. The program was started for the first 3 weeks in the Rehabilitation Clinic, Koenigstuhl, Heidelberg. It consisted of interval bicycle ergometer training at low workloads, mental gait training, dumbbell-training of single muscle groups using low weights $(500$ to $1000 \mathrm{~g})$ and respiratory therapy 5 days/ week. The training was continued at home with at least 30 minutes/day at 5 days/week for the following 12 weeks. Patients were asked to continue with ET at home after the 15-weeks-visit. In addition to physical training patients received psychological support and performed mental training to improve their perception of individual physical abilities and limits. Physicians specialized in rehabilitation medicine and $\mathrm{PH}$ experts closely supervised the training program as described before $[13,14]$. Adverse events were recorded whenever they occurred. Oxygen saturation and heart rate were monitored continuously throughout the training and used to adjust the training intensity. When patients' oxygen saturation fell below $90 \%$ during exercise they received supplemental oxygen $(3$ to $10 \mathrm{~L} / \mathrm{min}$ ) throughout the training. At 
discharge from hospital after 3 weeks, patients received an individualized training manual and ordered a bicycle ergometer for use at home. All patients were asked to keep close contact with the physicians involved in the training program, and with their general practitioners and the specialized center.

\section{Follow-up assessment}

In 2011 all participating patients were interviewed by telephone using a half-structured questionnaire. The patients were asked about their current symptoms for WHO-FC, if and how they pursued ET at home, whether they had any adverse events from ET, any further cardiac events that might have occurred since the last observation and current medication. Patients who did not attend the last 15-week follow-up visit were the reason for missing the examination. If the patient was deceased, date of death was recorded and their relatives and/or treating physicians were asked for the cause and circumstances of death.

\section{Statistical methods}

The analyses were performed by a statistician (CF). The within-group comparisons of baseline and weeks 3 and 15 for 6MWD, workload, Borg dyspnea index, parameters of gas exchange, systolic pulmonary arterial pressure (sPAP), systemic blood pressures, heart rate as well as summation and sub-scores of the SF-36 were compared by the Wilcoxon rank test. Comparison of WHO$\mathrm{FC}$ at different time points was performed by the $\mathrm{McNe}$ mar-Bowden test. All tests were two sided and $P$-values $<0.05$ were considered statistically significant. Bonferroni adjustment for multiple comparisons was performed for the primary endpoints, 6MWD and QoL parameters; $P$-values $<0.005$ were considered significant. All analyses were carried out using IBM SPSS V19 (IBM Corp. Armonk, NY, USA). We describe in detail, the patients who did not attend the 15 -week measurement. To access the consequences for the main efficacy parameter, 6MWD, we performed multiple imputations of $6 \mathrm{MWD}$ at 15 weeks within SPSS using the predictive mean matching model, with age, peak oxygen consumption, oxygen consumption at the AT, oxygen saturation at maximal workload, systolic blood pressure at maximal workload at baseline, 6MWD at baseline and 3 weeks, and pain subscale of the SF-36 at baseline as explanatory variables. Kaplan-Meier estimates were used for survival analysis with the $95 \%$ two-sided confidence interval (CI) calculated using Greenwood's formula. All treated patients were included in the survival analysis. Patients who died or underwent organ transplantation were counted as endpoints; survivors were regarded as censored.

\section{Results}

\section{Study population}

We included 22 consecutive patients (Table 1 ). One patient had to be excluded because she could not perform the examinations after week 3 and week 15, due to upper airway infection. Thus, the final study group consisted of 21 patients: 9 patients (43\%) with SSc-APAH, 7 (33\%) with SLE-APAH, 2 (10\%) with MCTD and 3

\section{Table 1 Baseline characteristics}

\begin{tabular}{|c|c|c|c|}
\hline Patients, number & & 21 & \\
\hline Gender male/female & 1 & / & 20 \\
\hline Age, years & 52 & \pm & 18 \\
\hline Height, cm & 165 & \pm & 6 \\
\hline Weight, kg & 68 & \pm & 11 \\
\hline WHO functional class, number (\%) & & & \\
\hline$\|$ & 9 & (43) & \\
\hline III & 7 & (33) & \\
\hline IV & 5 & (24) & \\
\hline Lung function & & & \\
\hline TLCO, \% & 55 & \pm & 18 \\
\hline FEV1\%VC, \% & 78 & \pm & 7 \\
\hline $\mathrm{pO} 2, \mathrm{mmHg}$ & 69 & \pm & 12 \\
\hline Mean 6-minute-walking distance, meter & & & \\
\hline & 386 & \pm & 121 \\
\hline Differential Diagnosis, number (\%) & & & \\
\hline Systemic sclerosis & 8 & $(43 \%)$ & \\
\hline Systemic lupus & 7 & $(33 \%)$ & \\
\hline MCTD & 2 & $(10 \%)$ & \\
\hline Others & 4 & $(14 \%)$ & \\
\hline Cardiac catherization & & & \\
\hline Pulmonary artery pressure, $\mathrm{mmHg}$ & 49 & \pm & 13 \\
\hline Pulmonary vascular resistance, dyn $\times \sec \times c m-5$ & 789 & \pm & 498 \\
\hline Right atrium pressure, $\mathrm{mmHg}$ & 7 & \pm & 3 \\
\hline Pulmonary artery oxygen saturation, $\%$ & 62 & \pm & 10 \\
\hline PCWP, $\mathrm{mmHg}$ & 10 & \pm & 5 \\
\hline Cardiac index, ${\mathrm{L} \times \mathrm{min} \times \mathrm{m}^{-2}}^{-2}$ & 2.6 & \pm & 0.6 \\
\hline PAH-targeted medication, number (\%) & & & \\
\hline Endothelin receptor antagonists & 12 & $(57 \%)$ & \\
\hline Phosphodiesterase-5-Inhibitors & 15 & $(71 \%)$ & \\
\hline Prostanoids inhaled & 3 & $(14 \%)$ & \\
\hline Prostanoids intravenous & 1 & $(5 \%)$ & \\
\hline Calcium channel blockers & 2 & $(10 \%)$ & \\
\hline Soluble guanyl cyclase-stimulator & 3 & $(14 \%)$ & \\
\hline Combination therapy, number (\%) & & & \\
\hline Monotherapy & 8 & $(38 \%)$ & \\
\hline Dual therapy & 10 & $(48 \%)$ & \\
\hline Triple therapy & 3 & (14\%) & \\
\hline
\end{tabular}

Results are presented as mean \pm standard deviation unless stated otherwise WHO: World Health Organization; FEV1\%VC: forced expiratory volume in one second/vital capacity; TLCO: carbon monoxide transfer factor; pO2: partial oxygen pressure; PCWP: pulmonary capillary wedge pressure; MCTD: mixed connective tissue disease. 
(14\%) with other CTDs such as Jo-1 syndrome and Sjöegren's syndrome. Demographic data, diagnosis, functional class, hemodynamic values, lung function and medical therapy in the full study population are summarized in Table 1. At baseline 9 patients (43\%) were in WHO-FC II, 7 (33\%) were classified as WHO-FC III and $5(24 \%)$ as WHO-FC IV. Combination therapies, including two to three PAH-targeted agents, were used in $62 \%$ of patients (Table 1 ).

\section{Assessment of training effects}

ET significantly improved the 6MWD from $386 \pm 121$ (mean \pm standard deviation (SD)) meters by $64 \pm 47$ meters after 3 weeks $(P<0.001)$ and by $71 \pm 35$ meters after 15 weeks $(P<0.003)$ (Figure 1$)$. All patients except one improved their 6MWD (Figure 1). In the patient with no increase in 6MWD the test was limited by her hip joint osteoarthritis. However, in this patient other parameters of physical exercise capacity improved during the ET.

Nine patients $(43 \%)$ referred from $\mathrm{PH}$-centers other than Heidelberg did not attend the visit after 15 weeks, mainly due to the long traveling distance. Results remained significant after multiple imputation of missing values for the 6MWD at 15 weeks using the explanatory variables as described in Methods. The improvement in 6MWD ranged from 71 to 79 meters in the imputation replications. Patients who did not attend the assessment after 15 weeks had a significantly higher peak oxygen consumption at the AT $(716 \pm 139$ vs. 543 $\pm 161 \mathrm{ml} / \mathrm{min} ; P=0.038)$ and a higher improvement in 6MWD (79 \pm 62 vs. $50 \pm 24$ meters; $P=0.156)$ after 3 weeks. They did not differ significantly in other parameters such as demographics or parameters of right heart catheterization. After Bonferroni adjustment, improvement in 6MWD remained statistically significant.

ET also significantly improved QoL parameters indicated by the SF-36 subscale scores for physical functioning $(P=0.025)$, general health perception $(P=0.049)$, social functioning $(P=0.008)$, mental health $(P=0.033)$ and vitality $(P=0.021)$ (Figure 2 , Table 2$)$.

Mean peak oxygen consumption, peak oxygen consumption $/ \mathrm{kg}$ body weight, oxygen consumption at the anaerobic threshold, and oxygen saturation at maximal workload during cardiopulmonary exercise testing increased significantly from baseline to 3 weeks and to 15 weeks (Table 2). Heart rate at rest significantly decreased after 3 and 15 weeks. After 15 weeks patients achieved significantly higher workloads with an increase of maximal heart rate during cardiopulmonary exercise testing and maximal systolic blood pressure. The Borg scale remained unchanged although significantly higher workloads and higher heart rates during exercise were attained (Table 2 Figure 3). After 3 weeks of ET, mean diastolic blood pressure and sPAP at rest were significantly reduced (Table 2). C-reactive protein reduced in trend, but not significantly, after 3 and 15 weeks,

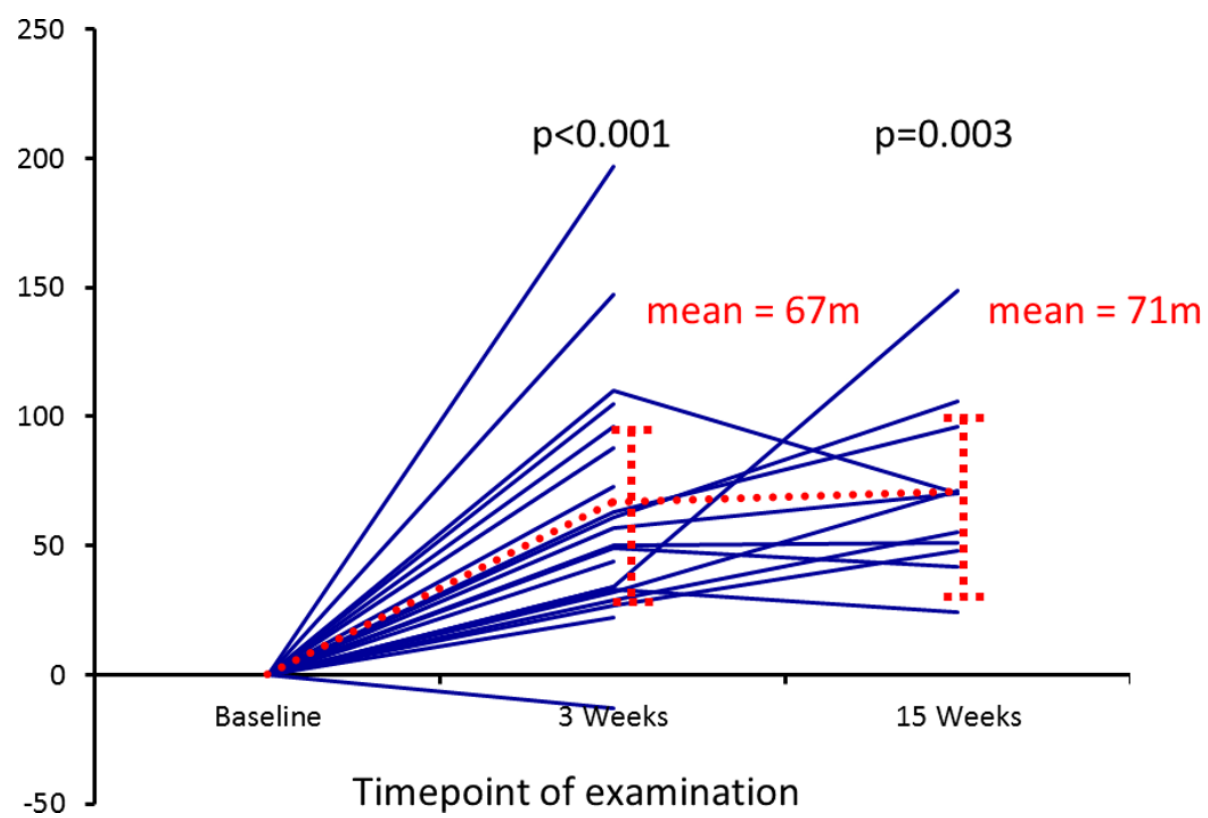

Figure 1 Individual changes in six-minute-walking distance (6MWD) after 3 and 15 weeks exercise training. Using the Wilcoxon rank test, $P<0.001$ was obtained for the comparisons with baseline at week $3(n=21)$ and $P=0.003$ for comparison to week $15(n=11)$. The dashed line indicates the mean change from baseline in 6MWD (67 \pm 52 meters and $72 \pm 35$ meters). 


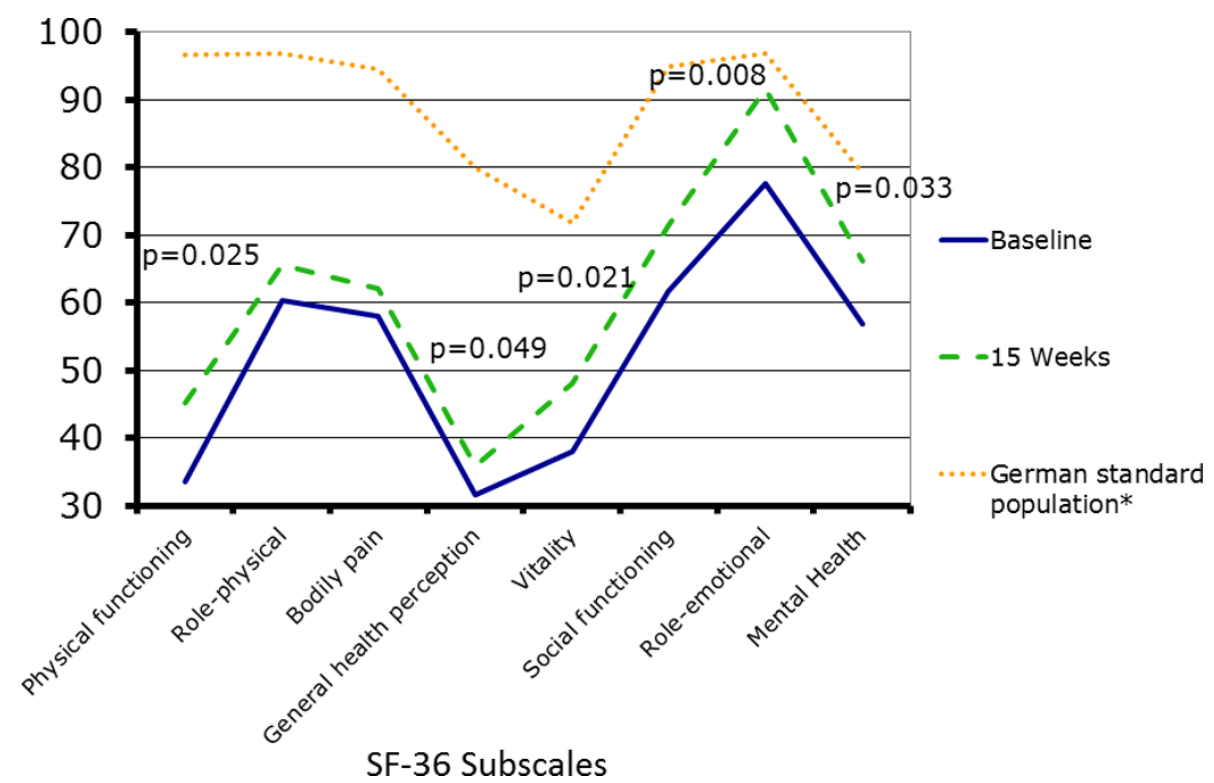

Figure 2 Mean short-form Health Survey Questionnaire (SF-36) scores for quality of life subscales before and after exercise training. At baseline (straight line), mean SF-36 scores were significantly reduced in comparison to respective values from a normal population (dotted line). After 15 weeks (dashed line), 5 scales of the SF-36 questionnaire improved significantly: physical functioning, general health perception, social functioning, mental health and vitality. P-values are indicated vs. baseline. No significant improvement was found for role emotional (ROLEM), role physical (ROLPH) and bodily pain (PAIN) after training. With Bonferroni adjustment, values of $P<0.005$ were considered statistically significant. Data were available and were included in the analyses for 21 patients studied at baseline and for 18 patients studied at 15 weeks.

whereas $\mathrm{N}$-terminal prohormone of brain natriuretic peptide (NT-proBNP) plasma-levels remained unchanged. Seven patients improved their WHO-FC after 15 weeks; five of them were reclassified as WHOFC IV. Nevertheless, the change in WHO-FC after 3 weeks and after 15 weeks compared to baseline was not significant $(P=0.058$ and $P=0.096$, respectively), possibly due to the small sample size.

\section{Adverse events}

During the 3-week in-hospital training, three patients had adverse events as follows: gastrointestinal infection with diarrhea $(n=1)$ and respiratory infections $(n=2)$. In all three patients the infection was treated successfully so that they were able to continue the training program after one or two weeks. All other patients (81\%) tolerated the ET well. There were no signs of clinical worsening or right heart failure during the in-hospital program.

\section{Follow-up and survival}

Follow-up data were obtained after $2.9 \pm 1.9$ years (Figure 4). One patient had been listed for lung transplantation before starting the rehabilitation program. She improved her walking distance by about 88 meters after 3 weeks, but did not perform the examination after 15 weeks due to the long traveling distance. However, she required lung transplantation 6 months later. Between
2.8 and 5.0 years after in-hospital rehabilitation, two patients died due to PAH and right heart failure, and one patient died due to cancer of unknown primary origin. The Kaplan-Meier PAH-survival rate was 100\% after 1 and 2 years, and $80 \%$ after 3 years (Figure 4). The overall survival rate was $100 \%$ after 1 and 2 years, and $73 \%$ after 3 years. The transplantation-free survival rate was 95\% after 1 and 2 years (Figure 4).

ET was continued over 3 years by 11 patients (61\%). They reported a mean ET-duration of $29 \pm 18$ minutes at $4 \pm 2$ days/week. Among the 11 patients, $44 \%$ continued bicycle ergometer training, 17\% dumbbell-training, $33 \%$ walking and $22 \%$ alternative training, such as gymnastics. Four patients (22\%) combined two training items and three patients (17\%) combined three items. Six patients (33\%) stopped exercise training for the following reasons: pain, presyncopes, no permanent instruction and confidence with general state of health.

\section{Discussion}

This is the first prospective clinical trial investigating short- and long-term effects of ET as an add-on to $\mathrm{PAH}$-targeted medication in patients with severe CTDAPAH. The results of the study suggest that ET can significantly improve prognostic relevant parameters such as exercise capacity and QoL in this condition, and has an excellent long-term survival of $100 \%$ after 2 years and $80 \%$ after 3 years. 
Table 2 Efficacy parameters

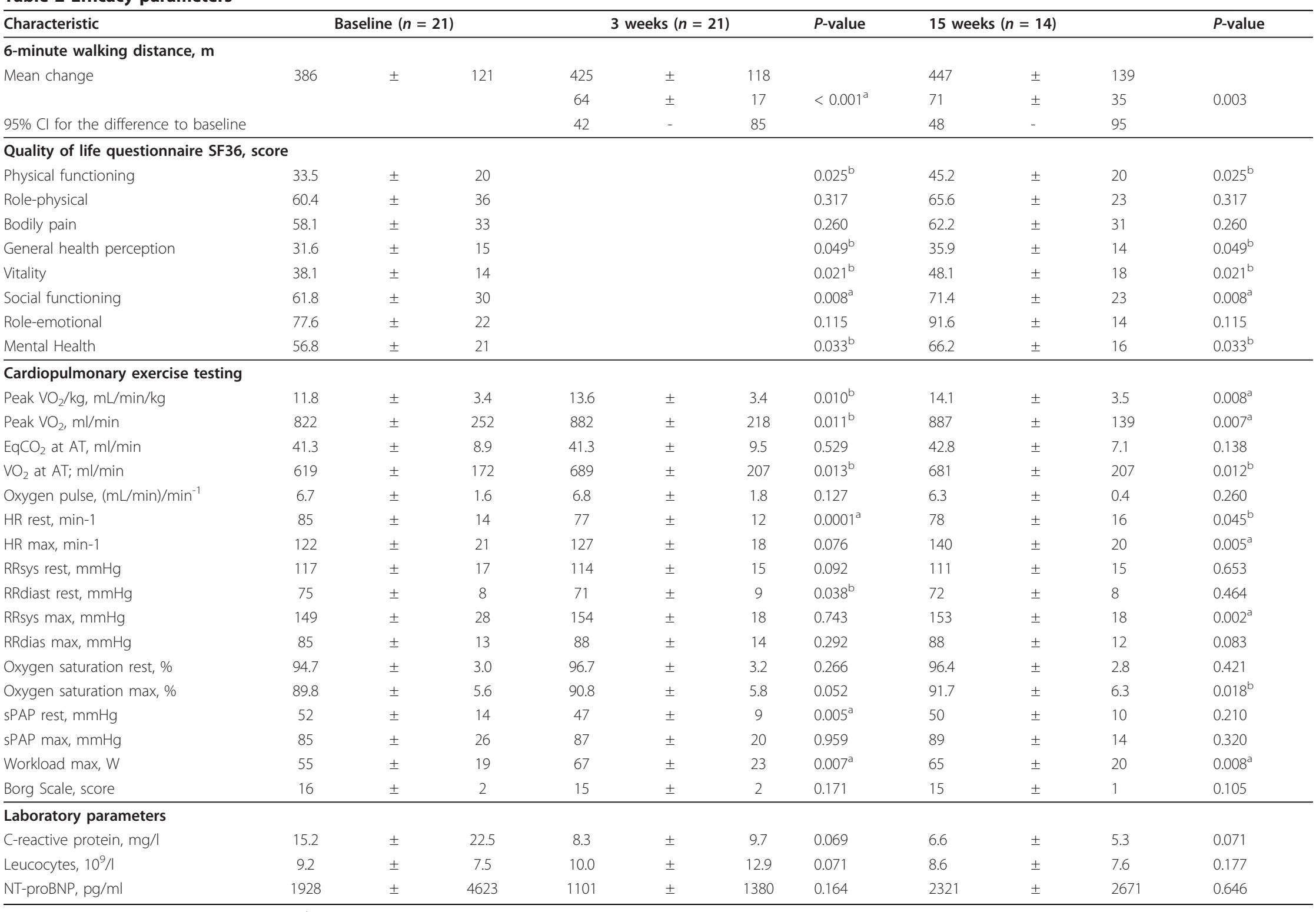

Values are mean \pm standard deviation. ${ }^{\mathrm{a}} P<0.01,{ }^{\mathrm{b}} P<0.05$ in comparison to baseline; $P$-values are the same for absolute values and differences. 6-minute walking distance data were analyzed by the two-sided Student $t$-test; cardiopulmonary exercise testing data were analyzed by the Wilcoxon test. Cl: confidence interval; SF-36: short-form Health Survey Questionnaire; $\mathrm{VO}_{2} / \mathrm{kg}$ : maximum oxygen consumption $/ \mathrm{kg}$; EqCO ventilatory equivalent for carbon dioxide; HR: heart rate; RRsys: systolic blood pressure; RRdiast: diastolic blood pressure; sPAP: systolic pulmonary arterial pressure; NT-proBNP: N-terminal prohormone of brain natriuretic peptide. 


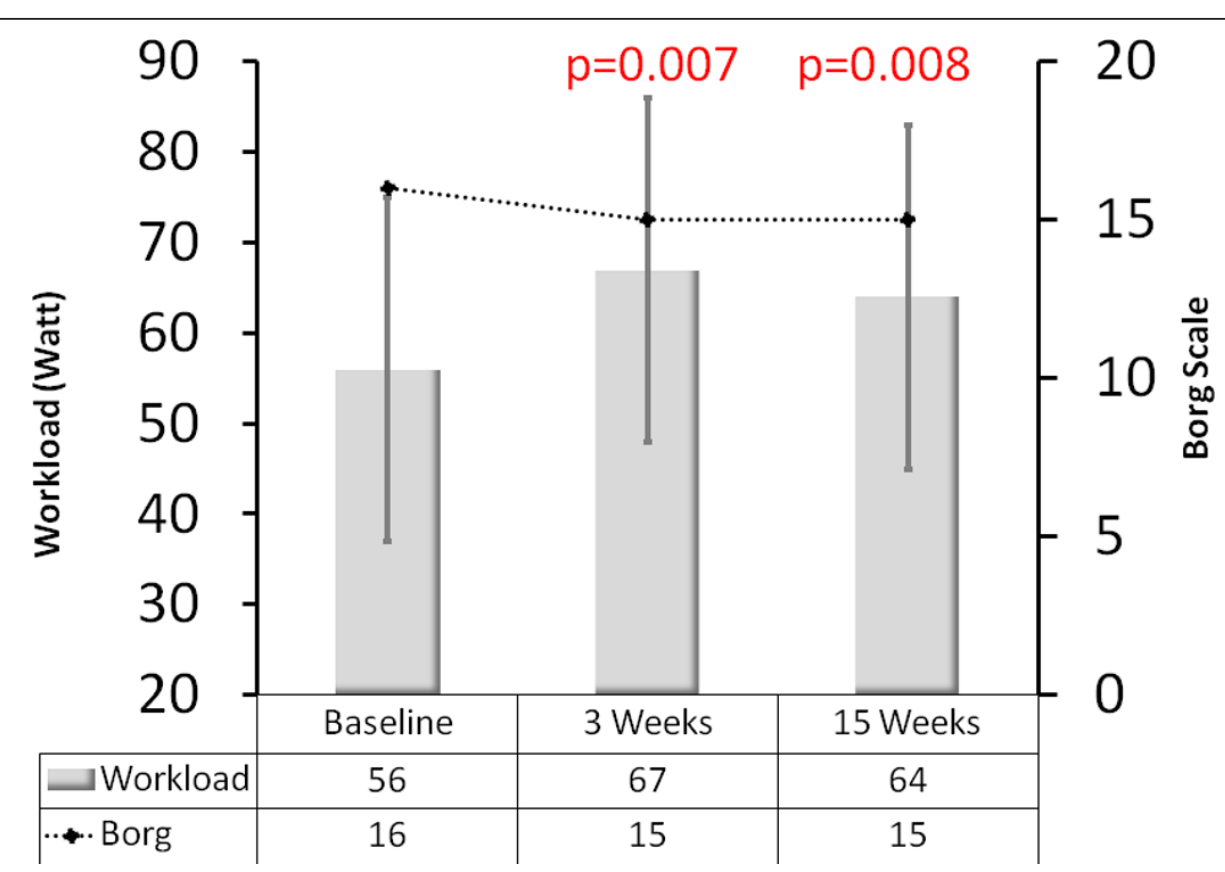

Figure 3 Workload compared to the Borg scale. The figure shows a significant increase in workload after 3 and 15 weeks $(P=0.007$ and $P=$ 0.008). The Borg scale remained unchanged $(P=0.171$ and $P=0.105$, respectively) although significantly higher workloads and higher heart rates during exercise were attained. Values are indicated as the mean, and the bars represent standard deviation. The columns represent workload (measured in Watt) and the dotted line the Borg Scale.

The results represent an important source of data on survival, exercise capacity and QoL in patients with CTD-APAH treated with ET. The 6MWD, QoL questionnaire (SF-36), peak oxygen consumption, oxygen consumption at the AT, maximal oxygen saturation and maximal workload increased significantly with ET

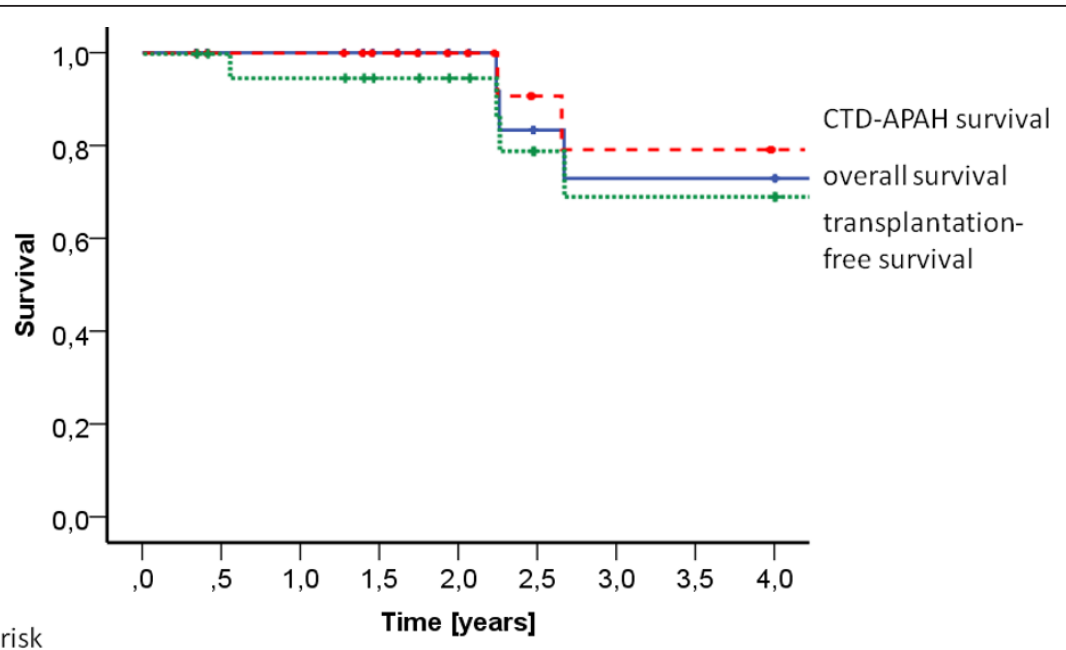

Patients at risk

\begin{tabular}{|c|c|c|c|c|c|}
\hline years & 0 & 1 & 2 & 3 & 4 \\
\hline$n$ & 21 & 19 & 13 & 7 & 7 \\
\hline
\end{tabular}

Figure 4 Survival by Kaplan-Meier analysis. Within a follow-up period of $2.9 \pm 1.9$ years ( $25 \pm 13$ months), two patients died due to pulmonary hypertension (PH), one died due to carcinoma, and one patient underwent lung transplantation. The dashed line indicates mortality due to connective tissue disease-associated pulmonary arterial hypertension (CTD-APAH), the straight line indicates overall survival, and the dotted line indicates transplantation-free survival. The Kaplan-Meier PAH-survival rate was 100\% after 1, and 2 years, and $80 \%$ after 3 years. The overall survival rate was 100\% after 1, and 2 years, and $73 \%$ after 3 years. The transplantation-free survival rate was $95 \%$ after 1 and 2 years. 
after 3 and 15 weeks. RRdiast and sPAP significantly decreased after 3 weeks. This may be due to an improvement in endothelial dysfunction. Nevertheless, due to the limited number of patients we cannot exclude that these improvements occurred coincidentally. The Borg scale remained unchanged although significantly higher workloads and higher heart rates during exercise were attained. These results are in line with previous studies of ET in patients with other forms of PH/PAH [13-15]. There are few data on exercise training in CTD. In patients with SSc but not PAH, ET has improved QoL parameters (SF-36) and heart rate at rest [19], 6 MWD [18] and muscle strength [17]. Quality of life and peak $\mathrm{VO}_{2}$ have also been significantly ameliorated by training in patients with SLE without PAH [16].

\section{Survival of patients with CTD-APAH after training}

The Kaplan-Meier overall survival rate of $100 \%$ after 1 and 2 years and $73 \%$ (80\% PH-related survival) after 3 years, using ET as add-on to optimized PAH-targeted medical treatment, can be considered a positive outcome in CTD-APAH. Despite optimized PAH-targeted therapy, the Reveal registry showed a 1-year survival in patients with SSC-APAH of only $82 \%$ vs. $84 \%$ in SLEAPAH, $88 \%$ in MCTD-APAH and $93 \%$ in IPAH [7]. In two trials of bosentan in CTD-APAH-patients, the Kaplan-Meier estimates of survival were $85.9 \%$ and 73.4\% after 1 and 2 years, respectively [23]. The 3-year survival rate in SSc-APAH was $60 \%$ vs. $78 \%$ in IPAH [8]. Similar patterns have been seen in the UK registry [9] and the French registry [24,25] and in several further studies [26]. These data indicate that patients with CTD-APAH represent a high-risk subgroup of patients with PAH. The CTD-APAH-cohort assessed in this study had been severely affected with a mean 6MWD of $386 \pm 121$ meters at baseline despite double or even triple PAH-targeted therapy in $62 \%$ of patients, and is therefore comparable to the cohorts described previously. We cannot exclude that we selected highly motivated and compliant patients with fewer outcome limitations. In addition, the number of patients in our study was quite small. Nevertheless, ET may have improved survival by ameliorating prognostic relevant factors such as QoL, exercise capacity and oxygen consumption. Since heart rate at rest, RRdiast and peak oxygen consumption significantly improved, ET possibly improved right ventricular reserve [14]. Similar effects of ET have been seen in patients with IPAH and CTEPH and right heart failure $[14,15]$.

\section{Improvement in 6-minute-walking distance}

The 6MWD has been used as primary endpoint in many randomized controlled clinical trials in PAH [1], and correlates with prognostic relevant clinical parameters such as WHO-FC in patients with SSc-PAH [6]. However, the test is not sufficiently validated in CTD-APAH and in patients with rheumatic diseases in particular, it is influenced by comorbidity and musculoskeletal limitations [6,27]. This has been taken as explanation for the fact that 6MWD in patients with CTD-APAH is at best only minimally improved by PAH-targeted medication. In randomized controlled trials, sildenafil is the only drug to have been associated with a significant increase in 6MWD in patients with CTD-APAH (in many other trials no subgroup analysis for this disease has been performed). Therefore, a mean increase of almost 70 meters after 3 and 15 weeks ET is unexpectedly high. The absence of a non-trained placebo group may be considered a limitation of the study, with concern that some of the improvements were due to the so-called placebo effect, rather than efficacy of ET. However, previously reported placebo-controlled $\mathrm{PAH}$ studies of bosentan or other PAH-specific treatments have not shown any clinically relevant improvements in the placebo groups. In fact, they have consistently shown a continuous decline in 6MWD. Therefore, the results of this study suggest that, especially in CTD-APAH-patients with known high coincidence of musculoskeletal limitations, ET as an add-on to PAH-targeted medication may be useful, and possibly even more effective in improving exercise capacity than medical treatment. Further randomized trials are needed to clarify this question.

\section{Limitations}

The results of this prospective study are promising and our data provide a good rationale for future studies of exercise training in patients with CTD-APAH. However, the positive results may also be influenced by the small sample size. Larger, randomized controlled and multicentric studies are needed to determine the effectiveness of exercise training in CTD-APAH. The effects of ET after 15 weeks may be biased due to the missing values of about $43 \%$ of patients who did not perform the last follow-up visit. A comparison between patients who completed the 15 week assessment and those who did not revealed that patients who dropped out had even better improvement in efficacy parameters after 3 weeks in-hospital rehabilitation. This suggests that they possibly did not attend because they felt better. Feedback from patients during follow-up visits supports this assumption.

It is a general issue of rehabilitation programs that the therapy cannot be performed in a blinded fashion and that a referral bias towards highly motivated patients with a better outcome may occur. Further studies are necessary to determine the effects of training programs on outcome in patients with $\mathrm{PH}$. 


\section{Conclusion}

This is the first trial investigating exercise training in CTD-APAH as an add-on to optimized medical therapy. The results indicate that ET is effective in CTD-APAH and may improve work capacity, QoL and further prognostic relevant parameters, and possibly improves the 1, 2- and 3-year survival rate. Further randomized controlled studies are needed to confirm these results.

\begin{abstract}
Abbreviations
APAH: associated pulmonary arterial hypertension; AT: anaerobic threshold; $\mathrm{Cl}$ : confidence interval; CTD: connective tissue disease; $\mathrm{EqCO}_{2}$ : ventilatory equivalent for carbon dioxide; ET: exercise training; FEV1\%VC: forced expiratory volume in one second/vital capacity; IPAH: idiopathic pulmonary arterial hypertension; MCTD: mixed connective tissue disease; 6MWD: six minute walking distance; NT-proBNP: N-terminal prohormone of brain natriuretic peptide; PAH: pulmonary arterial hypertension; PCWP: pulmonary capillary wedge pressure; $\mathrm{PH}$ : pulmonary hypertension; pO2: partial oxygen pressure; QoL: quality of life; REVEAL-Registry: Registry to Evaluate Early and long Term PAH Disease Management; RRdiast: diastolic systemic blood pressure; RRsys: systolic systemic blood pressure; SD: standard deviation; SF36: short form Health Survey Questionnaire; SLE: systemic lupus erythematosus; SPAP: systolic pulmonary arterial pressure; SSc: systemic sclerosis; TLCO: carbon monoxide transfer factor; VCO2: carbon dioxide output; VE: ventilation; VO2/heart rate: oxygen pulse; VO2: oxygen uptake; WHO-FC: World Health Organization functional class.
\end{abstract}

\section{Acknowledgements}

We would like to thank all patients who participated, and the patient association, Pulmonale Hypertonie eV, especially Bruno Kopp, for their support. We are grateful for the support of the clinic director Karl-Heinz Markmann, Alexander Heinz, all physicians especially Robert Nechwatal, Gabriele Karger, Soeren Uiker, the psychologist Volker Weigand, the therapists, and physiotherapists of the Rehabilitation Clinic Koenigstuhl, Heidelberg, who took part in the rehabilitation program. The study was funded by a grant from the German Pulmonary Hypertension Association; Pulmonale Hypertonie eV, Rheinstetten, Germany.

\section{Author details}

${ }^{1}$ Centre for Pulmonary Hypertension at Thoraxclinic Heidelberg, Thoraxclinic at the University Hospital Heidelberg, Amalienstraße 5, Heidelberg, 69126, Germany. ${ }^{2}$ Department of Human Genetics, University of Heidelberg, Im Neuenheimer Feld 366, Heidelberg, 69120, Germany. ${ }^{3}$ Department of Rheumatology, University of Heidelberg, Im Neuenheimer Feld 410, Heidelberg, 69120, Gemany. ${ }^{4}$ Department of Rheumatology, ACURA Centre for Rheumatic Diseases, Rotenbachtalstraße 5, Baden-Baden, 76530, Germany. ${ }^{5}$ Department of Internal Medicine, Medical Clinic III, Grafenstraße 9, Darmstadt, 64283, Germany. ${ }^{6}$ Centre for Pulmonary Hypertension, Clinic Löwenstein, Geißhölzle 62, Löwenstein, 74245, Germany. Department of Pneumology, University Hospital Gießen, Klinikstraße 33, Giessen, 35392, Germany. ${ }^{8}$ Department of Pneumology, University Hospital Dresden, Fetscherstraße 74, Dresden, 01307, Germany. 'Department of Pneumology, University Hospital Leipzig, Liebigstraße 20, Leipzig, 04103, Germany.

${ }^{10}$ Department of Neurology, University Hospital Heidelberg, Im Neuenheimer Feld 400, Heidelberg, 69126, Germany.

\section{Authors' contributions}

EG, CN and NE were responsible for designing the study, and conducting and analyzing the results and were directly involved in data collection. FM, FP and ML were directly involved in acquisition of data. CF was directly involved in analyzing and interpreting the results. NB, CF, FS, GS, FR, HT, MH, HJS and SW were principle investigators directly involved in data collection. All authors were involved in the writing of the manuscript and saw and approved the final version of the paper.

\section{Competing interests}

The authors declare that they have no competing interests.
Received: 14 February 2012 Revised: 30 April 2012

Accepted: 18 June 2012 Published: 18 June 2012

\section{References}

1. Galie N, Hoeper MM, Humbert M, Torbicki A, Vachiery JL, Barbera JA, Beghetti M, Corris P, Gaine S, Gibbs JS, Gomez-Sanchez MA, Jondeau G, Klepetko W, Opitz C, Peacock A, Rubin L, Zellweger M, Simonneau G, ESC Committee for Practice Guidelines (CPG): Guidelines for the diagnosis and treatment of pulmonary hypertension: The Task Force for the Diagnosis and Treatment of Pulmonary Hypertension of the European Society of Cardiology (ESC) and the European Respiratory Society (ERS), endorsed by the International Society of Heart and Lung Transplantation (ISHLT). Eur Heart J 2009, 30:2493-537.

2. Mukerjee D, St George D, Coleiro B, Knight C, Denton CP, Davar J, Black CM, Coghlan JG: Prevalence and outcome in systemic sclerosis associated pulmonary arterial hypertension: application of a registry approach. Ann Rheum Dis 2003, 62:1088-93.

3. Li EK, Tam LS: Pulmonary hypertension in systemic lupus erythematosus: clinical association and survival in 18 patients. J Rheumatol 1999, 26:1923-29.

4. Chung SM, Lee CK, Lee EY, Yoo B, Lee SD, Moon HB: Clinical aspects of pulmonary hypertension in patients with systemic lupus erythematosus and in patients with idiopathic pulmonary arterial hypertension. Clin Rheumatol 2006, 25:866-72.

5. Burdt MA, Hoffman RW, Deutscher SL, Wang GS, Johnson JC, Sharp GC: Long-term outcome in mixed connective tissue disease: longitudinal clinical and serologic findings. Arthritis Rheum 1999, 42:899-909.

6. Humbert M, Sitbon O, Chaouat A, Bertocchi M, Habib G, Gressin V, Yaici A, Weitzenblum E, Cordier JF, Chabot F, Dromer C, Pison C, ReynaudGaubert M, Haloun A, Laurent M, Hachulla E, Simonneau G: Pulmonary arterial hypertension in France: results from a national registry. Am J Respir Crit Care Med 2006, 173:1023-30.

7. Chung L, Liu J, Parsons L, Hassoun PM, McGoon M, Badesch DB, Miller DP, Nicolls MR, Zamanian RT: Characterization of connective tissue diseaseassociated pulmonary arterial hypertension from REVEAL: identifying systemic sclerosis as a unique phenotype. Chest 2010, 138:1383-94.

8. Clements PJ, Tan M, McLaughlin W, Oudiz RJ, Tapson VF, Channick RN, Rubin LJ, Langer A, Pulmonary Arterial Hypertension Quality Enhancement Research Initiative (PAH-QuERI) Investigators: The pulmonary arterial hypertension quality enhancement research initiative: comparison of patients with idiopathic $\mathrm{PAH}$ to patients with systemic sclerosisassociated PAH. Ann Rheum Dis 2012, 71:249-52.

9. Condliffe R, Kiely D, Peacock AJ, Corris PA, Gibbs JS, Vrapi F, Das C, Elliot CA Johnson M, DeSoyza J, Torpy C, Goldsmith K, Hodgkins D, Hughes RJ, Pepke-Zaba J, Coghlan JG: Connective tissue disease-associated pulmonary arterial hypertension in the modern treatment era. Am J Respir Crit Care Med 2009, 179:91-92.

10. Goldberg A: Pulmonary Arterial Hypertension in Connective Tissue Diseases. Cardiol Rev 2010, 18:85-88

11. Rubin LJ, Badesch DB, Barst RJ, Galie N, Black CM, Keogh A, Pulido T, Frost A, Roux S, Leconte I, Landzberg M, Simonneau G: Bosentan therapy for pulmonary arterial hypertension. N Engl J Med 2002, 346:896-903.

12. Galie N, Olschewski H, Oudiz RJ, Torres F, Frost A, Ghofrani HA, Badesch DB, McGoon MD, McLaughlin W, Roecker EB, Gerber MJ, Dufton C, Wiens BL, Rubin LJ, Ambrisentan in Pulmonary Arterial Hypertension, Randomized, Double-Blind, Placebo-Controlled, Multicenter, Efficacy Studies (ARIES) Group: Ambrisentan for the treatment of pulmonary arterial hypertension: results of the ambrisentan in pulmonary arterial hypertension, randomized, double-blind, placebo-controlled, multicenter, efficacy (ARIES) study 1 and 2. Circulation 2008, 117:3010-19.

13. Mereles D, Ehlken N, Kreuscher S, Ghofrani S, Hoeper MM, Halank M, Meyer FJ, Karger G, Buss J, Juenger J, Holzapfel N, Opitz C, Winkler J, Herth FF, Wilkens H, Katus HA, Olschewski H, Grünig E: Exercise and respiratory training improve exercise capacity and quality of life in patients with severe chronic pulmonary hypertension. Circulation 2006, 114:1482-89.

14. Grünig E, Ehlken N, Ghofrani A, Staehler G, Meyer FJ, Juenger J, Opitz CF, Klose H, Wilkens H, Rosenkranz S, Olschewski H, Halank M: Effect of exercise and respiratory training on clinical progression and survival in patients with severe chronic pulmonary hypertension. Respiration 2011, 81:394-401. 
15. Grünig E, Lichtblau M, Ehlken N, Ghofrani HA, Reichenberger F, Staehler G, Halank M, Fischer C, Seyfarth HJ, Klose H, Meyer A, Sorichter S, Wilkens H, Rosenkranz S, Opitz C, Leuchte H, Karger G, Speich R, Nagel C: Safety and efficacy of exercise training in various forms of pulmonary hypertension. Eur Respir $\mathrm{J}$.

16. Carvalho MR, Sato El, Tebexreni AS, Heidecher RT, Schenkman S, Neto TL: Effects of supervised cardiovascular training program on exercise tolerance, aerobic capacity, and quality of life in patients with systemic lupus erythematosus. Arthritis Rheum 2005, 53:838-44.

17. Pinto ALS, Oliveira NC, Gualano B, Christmann RB, Painelli VS, Artioli GG, Prado DM, Lima FR: Efficacy and safety of concurrent training in systemic sclerosis. J Strength Cond Res 2011, 25:1423-28.

18. Schouffoer AA, Ninaber MK, Beaart-van de Voorde LJ, van der Giesen FJ, de Jong Z, Stolk J, Voskuyl AE, Scherptong RW, van Laar JM, Schuerwegh AJ, Huizinga TW, Vlieland TP: Randomized comparison of a multidisciplinary team care program with usual care in patients with systemic sclerosis. Arthritis Care Res 2011, 63:909-17.

19. Antonioli CM, Bua G, Frigè A, Prandini K, Radici S, Scarsi M, Danieli E, Malvicini A, Airo P: An individualized rehabilitation program in patients with systemic sclerosis may improve quality of life and hand mobility. Clin Rheumatol 2009, 28:159-65.

20. Guyatt GH, Pugsley SO, Sullivan MJ, Thompson PJ, Berman L, Jones NL, Fallen EL, Taylor DW: Effect of encouragement on walking test performance. Thorax 1984, 39:818-22.

21. Borg G: Psychophysical bases of perceived exertion. Med Sci Sports Exerc 1982, 14:377-81.

22. Ware J, Sherbourne C: The MOS 36-Item Short-Form Health Survey (SF36): I. conceptual framework and item selection. Medical Care 1992, 30:473-83.

23. Denton CP, Pope JE, Peter HH, Gabrielli A, Boonstra A, van den Hoogen FH, Riemekasten G, De Vita S, Morganti A, Dölberg M, Berkani O, Guillevin L, TRacleer Use in PAH associated with Scleroderma and Connective Tissue Diseases (TRUST) Investigators: Long-term effects of bosentan on quality of life, survival, safety and tolerability in pulmonary arterial hypertension related to connective tissue diseases. Ann Rheum Dis 2008, 67:1222-28.

24. Hachulla E, Launay D, Yaici A, Berezne A, de Groote P, Sitbon O, Mouthon L, Guillevin L, Hatron PY, Simonneau G, Clerson P, Humbert M, French PAH-SSC Network: Pulmonary arterial hypertension associated with systemic sclerosis in patients with functional class II dyspnoea: mild symptoms but severe outcome. Rheumatology 2010, 49:940-944.

25. Humbert M, Sitbon O, Chaouat A, Bertocchi M, Habib G, Gressin V, Yaïci A, Weitzenblum E, Cordier JF, Chabot F, Dromer C, Pison C, ReynaudGaubert M, Haloun A, Laurent M, Hachulla E, Cottin V, Degano B, Jaïs X, Montani D, Souza R, Simonneau G: Survival in patients with idiopathic, familial, and anorexigen-associated pulmonary arterial hypertension in the modern management era. Circulation 2010, 122:156-63.

26. Johnson SR, Granton JT: Pulmonary hypertension in systemic sclerosis and systemic lupus erythematosus. Eur Respir Rev 2011, 20:277-86.

27. Impens AJ, Wangkaew S, Seibold JR: The 6-minute walk test in scleroderma-how measuring everything measures nothing. Rheumatology 2008, 47:68-69.

\section{doi:10.1186/ar3883}

Cite this article as: Grünig et al:: Exercise training in pulmonary arterial hypertension associated with connective tissue diseases. Arthritis Research \& Therapy 2012 14:R148.

\section{Submit your next manuscript to BioMed Central and take full advantage of:}

- Convenient online submission

- Thorough peer review

- No space constraints or color figure charges

- Immediate publication on acceptance

- Inclusion in PubMed, CAS, Scopus and Google Scholar

- Research which is freely available for redistribution

Submit your manuscript at www.biomedcentral.com/submit 